\title{
XXI Festival Iberoamericano de Teatro de Cádiz 2006: Espacio de intercambio de ideas y de dramaturgias contemporáneas
}

\section{Miguel Ángel Giella}

Del 17 al 28 de octubre se celebró en Cádiz la XXI edición del Festival Iberoamericano de Teatro que en esta ocasión contó con la participación de 28 grupos: 13 latinoamericanos, 12 españoles y tres coproducciones España-Latinoamérica. En total se tenía previsto realizar 45 representaciones, aunque de las 12 programadas como espectáculos de calle no todas se pudieron presentar, por lo menos en los días anunciados, debido a las inclemencias del tiempo. Pero ni el temporal que azotó con fuerza durante varias jornadas fue impedimento para que gran parte de los 800 invitados llegados de todo el mundo, entre los que se encontraban periodistas, críticos, autores, directores, actores, actrices y hasta el mismo público gaditano, dejaran de asistir a los distintos montajes que se ofrecían diariamente en las salas y teatros de esta bella ciudad andaluza. Entre los países participantes figuran Argentina, Bolivia, Brasil, Chile, Colombia, Cuba, México, Perú, Uruguay y España.

\section{Espectáculos y actividades con protagonismo femenino}

Con ocasión de la celebración del X Encuentro de Mujeres de Iberoamérica en las Artes Escénicas cuyo tema fue La memoria en el futuro, se programaron una serie de espectáculos plenamente femeninos en su temática o en su vertiente creativa. México estuvo presente con dos montajes que intentan recuperar su pasado cultural: Sa'as Tun puso en escena Mestiza Power. Retrato de la mujer maya contemporánea, con dramaturgia y dirección de Concepción León Mora, y Las Patronas, presentaron El maiz, con la actuación de Jesusa Rodríguez y la música e interpretación de Liliana Felipe. Mestiza Power cuenta tres historias desgarradoras a las que se enfrentan tres mujeres indígenas de cultura maya con admirable firmeza; 


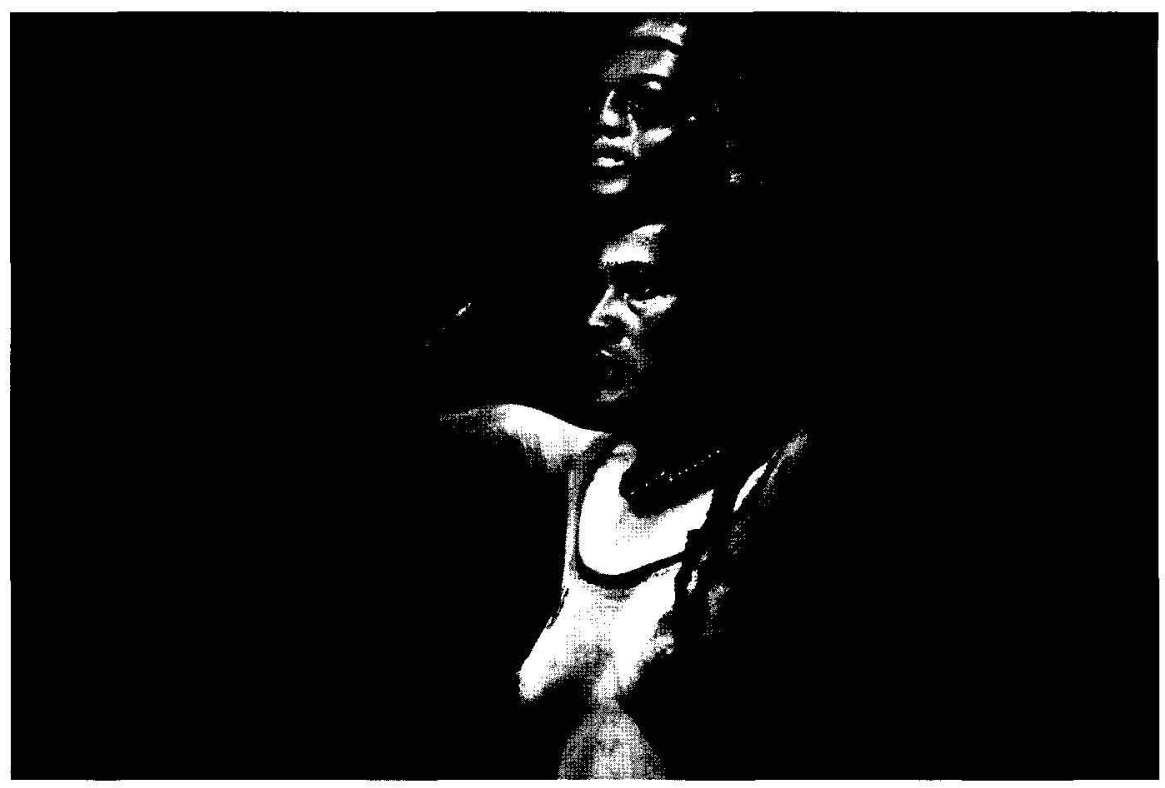

Las patronas Foto: Manuel Fernández.

mientras que El maiz es una defensa de este producto básico en la alimentación y economía mexicana que se encuentra amenazado por la entrada al país de toneladas de maíz transgénico procedente del norte. Destaca la actuación de Jesusa Rodríguez. Esta combativa actriz del DF aparece en escena luciendo una malla transparente, rodeada de vasijas con tintes de colores con los que ornamenta su cuerpo, reinterpretando con gran belleza el antiguo mito del origen de los hombres de maíz. La protagonista se sirve de la farsa y del humor negro para reivindicar la diversidad cultural de la sociedad mexicana.

La chilena Manuela Infante presentó Narciso, obra premiada en Chile como mejor texto y mejor dirección de 2005. La pieza se desarrolla en un espacio reducido: los espectadores se encuentran sentados en gradas a ambos lados del rectángulo en el que transcurre la acción dramática. Narciso muestra un ritual y un juego de espejos de adolescentes del estado de bienestar enfrentados al suicidio. Esta sería la anécdota básica porque detrás de la puesta, según declaraciones de la propia Infante, hay "una profunda investigación teórica y práctica que pretende - mediante un relato simple y entretenido, un trabajo actoral con fuertes acentos físicos y un humor agudo y corrosivo - dialogar con la imagen de nosotros mismos." Notable actuación 


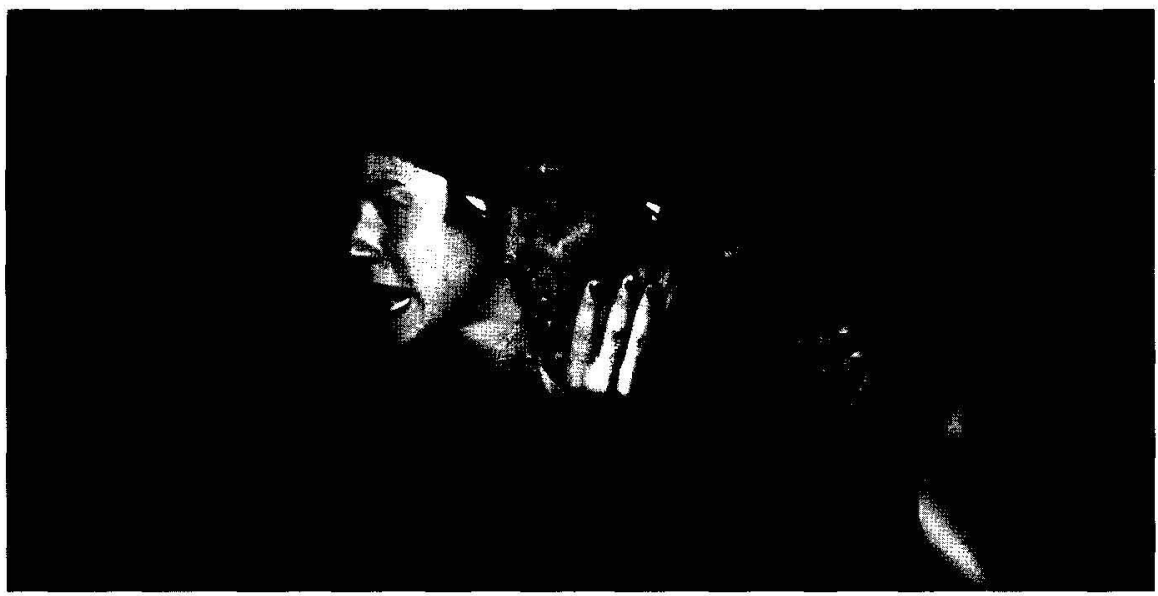

Narciso Foto: Manuel Fernández.

de Angélica Vial y Rodrigo Sobarzo de un texto que resulta estremecedor al retratar con desparpajo y soltura las vidas vacías y sin esperanza de dos adolescentes que habitan en cualquiera de nuestras ciudades. El público y la crítica consideraron este espectáculo como uno de los preferidos del festival.

Diva Producciones del Perú presentó el montaje de Ruth Escudero El guía del Hermitage de Hebert Morote, Premio Kutxa Ciudad de San Sebastián. La pieza trata del traslado a los Urales de las obras del Hermitage durante el cerco de Leningrado, y de la decisión del viejo guía del museo de continuar las visitas guiadas y explicar cuadros - que ya no estaban - a un público - que ya no existía. Al principio, tanto la esposa del guía como el guardia del museo se resisten a dar crédito a las fantasías del anciano. Hacia el final, ellos también ven los cuadros, y tras la muerte del guía, deciden continuar y mantener viva su ilusión, una manera de sobrevivir ante el horror que los rodea. Buen trabajo de interpretación, en especial la de Hernán Romero en el papel del guía.

La coproducción hispano-argentina Olimpia, o la pasión de existir de Margarita Borja, con dramaturgia de escenas dialogadas a cargo de Diana Raznovich, de la compañía alicantina Teatro de las Sorámbulas y de la argentina Armar Artes, fue otro de los espectáculos enclavados dentro del X Encuentro de Mujeres. La puesta rescata la figura y la obra de Olimpia de Gougues, revolucionaria francesa, precursora del feminismo moderno y escritora de teatro. Esta combativa y lúcida intelectual acabó sus días en el cadalso. El espectáculo incorpora la proyección de vídeos y la filmación digital de escenas 
que sirven para contextualizar diferentes momentos en los que se desarrolla la acción dramática.

El Centro Andaluz de Teatro y Producciones Imperdibles presentaron Zenobia, con dirección y puesta en escena de Gema López y José María Roca, obra en la que se recrea la historia de Zenobia Camprubí, compañera y esposa del poeta Juan Ramón Jiménez, Premio Nobel de Literatura en 1956. El espacio escénico está formado por dos pantallas que ocupan parte del escenario. En ellas se proyectan imágenes grabadas e imágenes en directo producidas por una cámara que se encuentra en el mismo escenario. Zenobia y Juan Ramón son filmados durante toda la representación, mientras una pianista acompaña con su música distintos momentos de la acción. Resulta significativa la aportación de los medios audiovisuales puesto que complementan la acción dramática - como, por ejemplo, mostrando los viajes por América, los lugares donde vivió la pareja durante su exilio o reportajes periodísticos de la Guerra Civil - a la vez que enriquecen esta innovadora propuesta andaluza.

Mujeres con cajones, concierto musical de la aragonesa Carmen París y la cubana Albita, forma parte de la gira itinerante Fémina'06 organizada por la Fundación Autor para promover la creación en femenino. Se anunciaba como un concierto diferente $y$, a decir verdad, lo fue. Carmen París con su

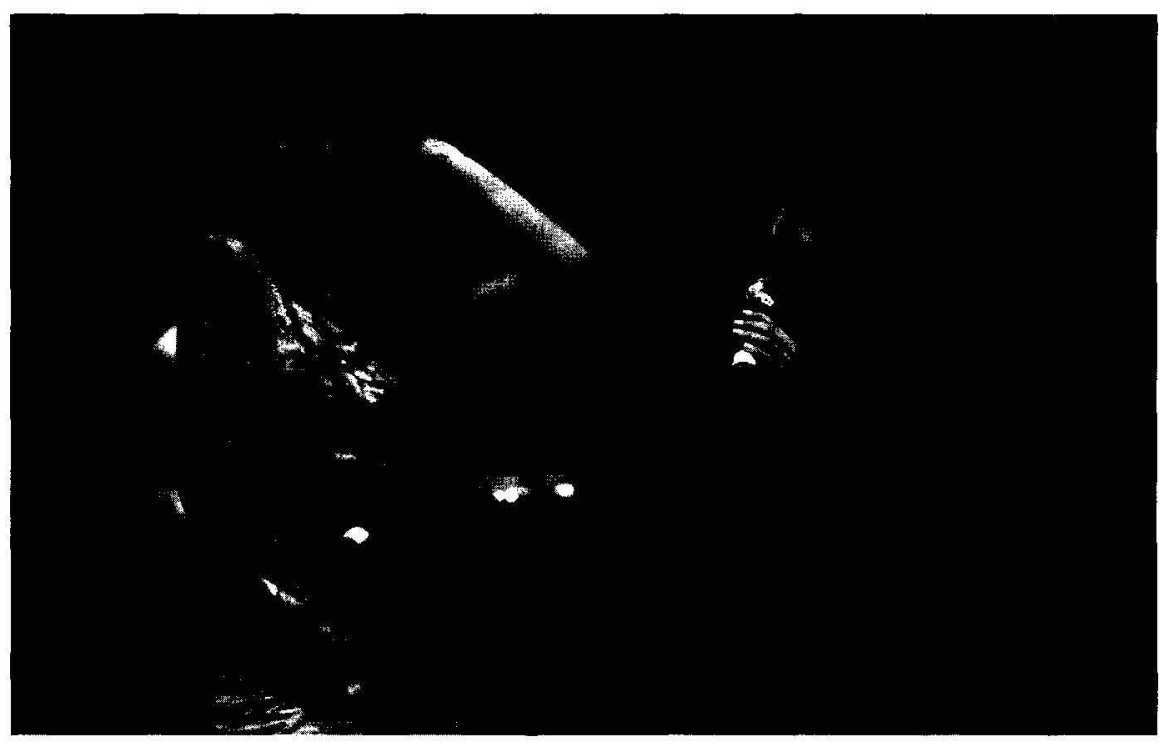

Mujeres con cajones Foto: Manuel Fernández. 
llamada "jota-fusión" armoniza la jota con otros ritmos que van "desde el valle del Ebro, hasta el Río de la Plata." Mientras que Albita - con dos Grammy al Mejor Álbum Tropical y como productora del mismo en su haber - reinventa la tradición mezclando y fusionando ritmos como el son y el rap para crear nuevas melodías. Ambas, con mucho desenfado y con aires muy personales deleitaron a un público que aplaudió entusiasta este concierto único y sorprendente.

Hemos decidido incluir dentro de este apartado dos importantes distinciones que entrega anualmente el FIT en el Salón de Plenos del Ayuntamiento de Cádiz y que este año han recaído en dos destacadas actrices: el VII Premio Atahualpa del Cioppo a la uruguaya Nidia Telles por su brillante carrera sobre los escenarios, y el homenaje a la española María Jesús Valdés en reconocimiento a su extensa trayectoria profesional.

\section{Dramaturgias actuales}

Las propuestas teatrales citadas en el apartado anterior se completan con otras que a continuación señalamos. Argentina fue el país latinoamericano que contó con más representación en Cádiz al reunir a cinco compañías, entre las que se encontraba Armar Artes, que como hemos visto, presentó Olimpia. La otras cuatro fueron: Equipo Teatro Llanura con Como un puñal en las carnes, Proyecto Chejov con Un hombre que se ahoga, Compañía Jorge Sánchez con Nadar abraza y Niño Costrini con su espectáculo de calle Costrini.

Como un puñal en las carnes de Mauricio Kartun, bajo la dirección de Alfredo Catania, cuenta las vicisitudes de un veterano empleado de banca, Monterito, que un día decide abandonarlo todo - mujer, hijo, hogar, empleoy escapar a Mar del Plata con una adolescente encargada del servicio doméstico en su casa. El actor Jorge Ricci, interpreta con muy pocos elementos y mucho oficio este monólogo en el que, a través de tres momentos - la duda, la pasión, la derrota - construye un personaje desvalido que resulta tragicómico. El título de la obra, sacado de una frase del tango Pasiona, resume de forma tanguera el amor-pasión que siente Monterito por esta Lolita argentina.

Un hombre que se ahoga, versión de Tres hermanas de Antón Chejov, escrita y dirigida por Daniel Veronese, fue una de las propuestas más atrayentes de este festival. El texto del conocido dramaturgo ruso fue llevado a escena desde una mirada actual, respetando su estructura, pero, al mismo tiempo, con claros rasgos de contemporaneidad. La originalidad de 


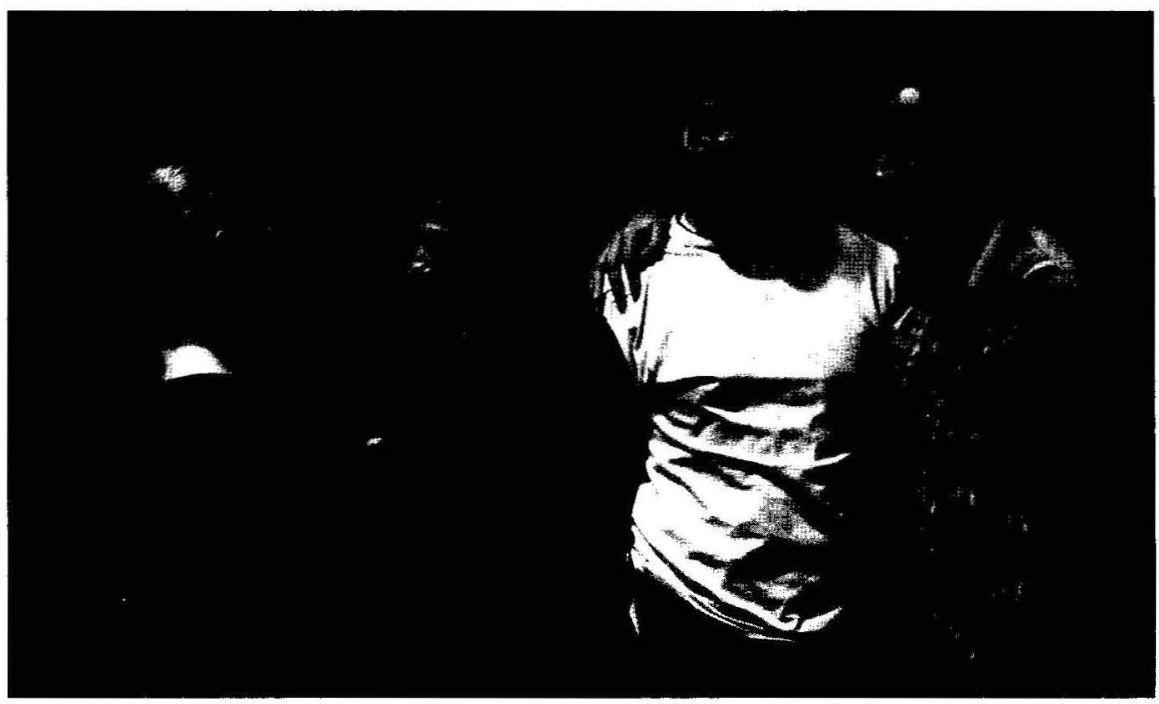

Un hombre que se ahoga Foto: Manuel Fernández.

esta puesta radica, por un lado, en que los personajes femeninos son interpretados por hombres y los masculinos por mujeres y, por otro, que tanto los actores como las actrices - doce en total, vestidos con ropa de calle permanecen durante toda la obra en el escenario. El espacio escénico es reducido: al fondo, una fila de butacas de teatro desde donde miran e intervienen los personajes; un espacio central con un sofá de dos plazas en el que tienen lugar casi todas las escenas, $y$, al borde del escenario, una fila de sillas en las que se sientan, de espaldas al público, aquellos personajes que no intervienen en determinado momento, aunque, a veces, también se utilizan las sillas según exigencias de la acción dramática. La inutilidad de la vida de estos seres y su incapacidad para librarse de la mediocridad en la que están inmersos es el eje sobre el cual gira la obra. Tensiones y afectos que se observan a través de una excelente actuación y acertada dirección de Daniel Veronese.

Nadar abraza, con dramaturgia de Jorge Sánchez y Gustavo Palacios y dirección del mismo Sánchez, reúne a cuatro actores y seis actrices procedentes de Argentina y España. La pieza toma como punto de partida una historia de Raymond Carver, en la que unos amigos se van de pesca y encuentran el cadáver de una mujer flotando en el río, a la que se unen otras historias y textos. A través de la representación se pone de relieve el intenso 


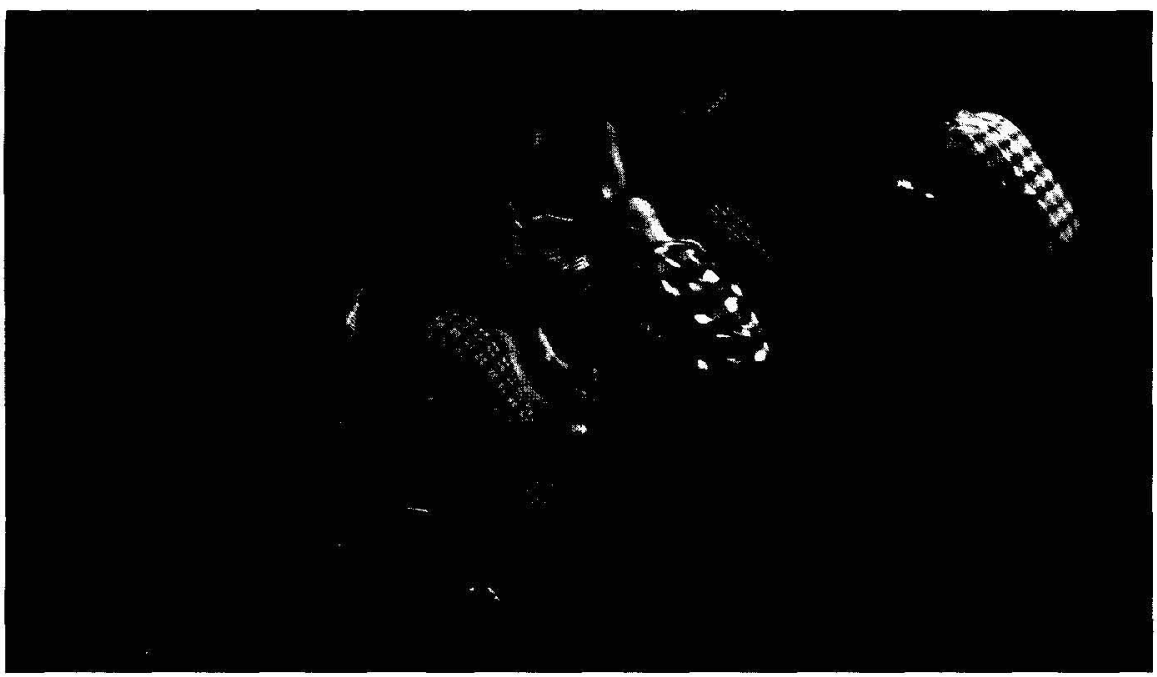

Nadar abraza Foto: Manuel Fernández.

trabajo actoral del grupo. La magnífica coreografía de este espectáculo se sustenta sobre todo en "la acción física, la biomecánica y el minimalismo, con la exigencia de un duro trabajo corporal, aunque también se intercalan fragmentos que parecen parodiar el musical de Broadway" (Désirée Ortega Cerpa, Diario de Cádiz, 29-10-06). Buen texto y mejor actuación de esta novel compañía hispano-argentina.

Teatro del Mercado (Uruguay) presentó De la gaseosa al champán del español Javier Rey de Sola, con dirección de Marcelino Duffau. Un empresario corrupto se encuentra en la cárcel junto a su fiel empleado. El lugar produce cambios insospechados en estos dos hombres: el empleado pasa del total sometimiento a su jefe a ser uno de los cabecillas dentro de la prisión, mientras que el empresario acepta su nuevo papel de forma sumisa. Tal vez aquí radique uno de los puntos débiles del texto ya que el proceso de transformación de ambos personajes resulta abrupto, por tanto, no creíble. Sin embargo, la veteranía de los actores salva la puesta en clave de humor y sátira.

Uroc Teatro en colaboración con el Centro Dramático Nacional (España) puso en escena El señor Ibrahim y las flores del Corán, versión teatral y dirección de Ernesto Caballero sobre el relato de Eric-Emmanuel Schmitt. La obra tiene lugar en el París de los años sesenta, y cuenta la amistad entre un solitario y reflexivo tendero árabe, Ibrahim, dotado de una 


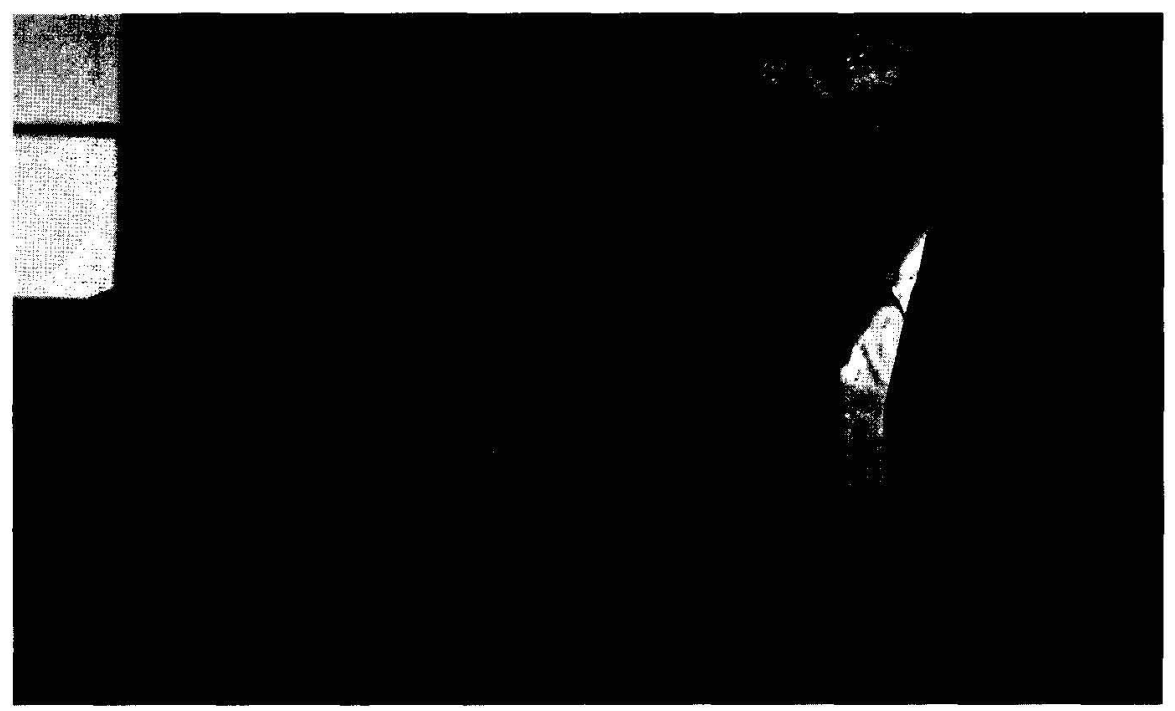

El señor Ibrahim Foto: Manuel Fernández.

gran sabiduría, y un inquieto adolescente judío llamado Momó. A través de la acción lo que básicamente se transmite es que, por un lado, hay gente que ayuda a los demás sin esperar nada a cambio y, por otro, que dos personas,

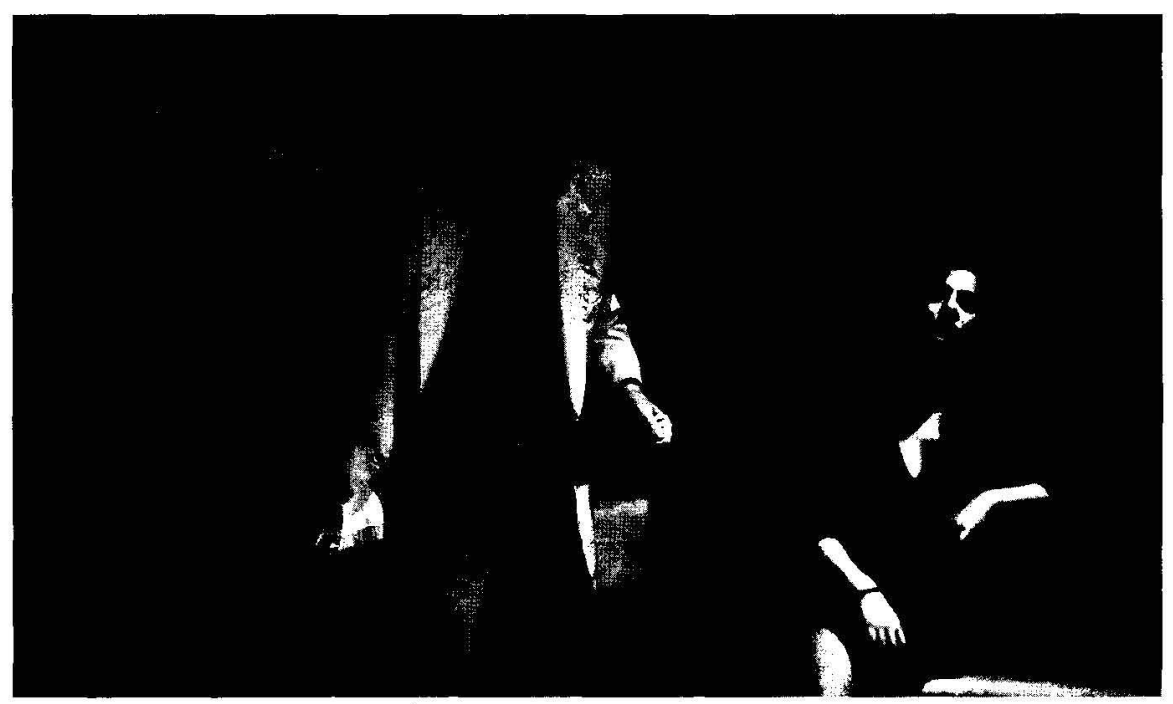

El túnel Foto: Manuel Fernández. 
sean de la religión que sean, se pueden entender y apoyar. La escenografia es detallista (reproduce una tienda de comestibles) en acertados tonos ocres; al fondo, un gran cristal opaco en el que se lee "Ibrahim. Épicerie." La estupenda interpretación de Juan Margallo del anciano Ibrahim le valió el Premio Max al mejor actor de 2006, nunca mejor merecido.

La adaptación de Diego Curatella de El túnel de Ernesto Sábato fue la segunda puesta en este FIT dirigida por Daniel Veronese, que contó con la actuación del reconocido actor argentino Héctor Alterio en el papel de Juan Pablo Castel. Para todos aquellos que hemos leído la novela de Sábato algunos pasajes nos resultaron familiares ya que la obra respeta y sigue muy de cerca el texto original. El enfoque elegido por el adaptador con la anuencia del escritor fue hacer que Castel rememorase 40 años después, con la complicidad del espectador, sus recuerdos; recuerdos que son a su vez teatralizados por otros personajes. Se observa el toque Veronese tanto en la disposición de la escena como en la sobria interpretación de los actores. Héctor Alterio resuelve con maestría un personaje de gran complejidad interpretativa.

El grupo sevillano Atalaya presentó La ópera de tres centavos de Bertolt Brecht con dirección, espacio escénico y adaptación del texto a cargo de Ricardo Iniesta. Un conjunto de estructuras metálicas sirven para construir los distintos espacios donde se desarrolla la acción. Cuatro actores y tres actrices se transforman, con un vestuario acorde, en 16 personajes, mientras otros siete músicos interpretan, a un lado del escenario, la música de Kurt Weill. Predomina lo grotesco, la denuncia social y el cabaret. El montaje, que cuenta con movimientos escénicos bastante complejos, puso de relieve un importante esfuerzo actoral y de dirección.

Camaleón Producciones y Ernesto Calvo Producciones (España) presentaron Minetti, de Thomas Bernhard, con dirección y dramaturgia de Ernesto Calvo. La pieza, que lleva como título el nombre del famoso actor alemán fallecido en 1998, más que una biografía es una reflexión sobre la decadencia y el fracaso. Ni el texto ni la actuación, un tanto afectada, entusiasmaron al público.

Teatro Corsario (España) llevó a escena La barraca de Colón, creación y dirección de Fernando Urdiales. La acción se desarrolla en una especie de barraca de feria donde una trouppe de artistas circenses domadores de fieras, clowns, titiriteros y equilibristas - recrean con mucha imaginación la azarosa vida de Cristóbal Colón. El humor y la ironía recorren este montaje que muestra los vaivenes del poder y la ascensión y caída del 


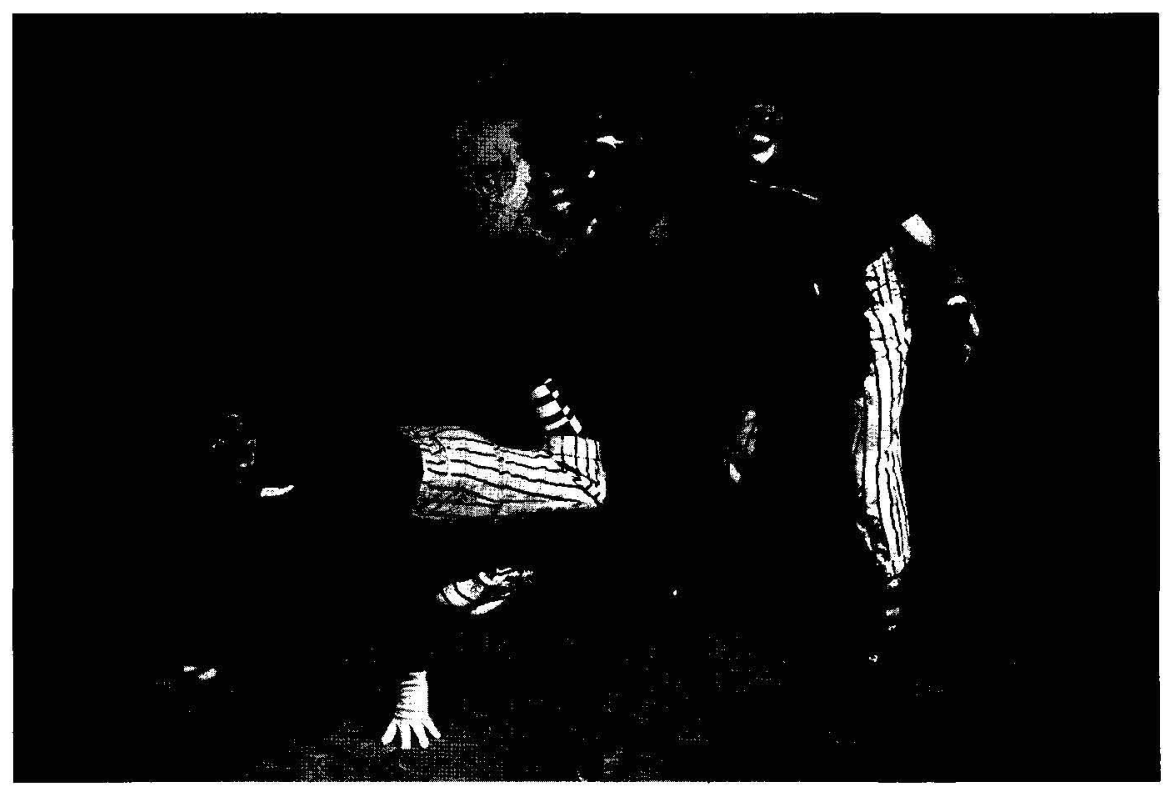

La barraca de Colón Foto: Manuel Fernández.

Almirante. El grupo de actores encarna de manera relevante los distintos personajes que desfilan a lo largo de esta puesta en clave de comedia musical.

Como ha ocurrido en otros años, la histórica compañía catalana Els Joglars volvió a clausurar el festival, en esta ocasión con su última puesta: En un lugar de Manhattan, dramaturgia y dirección de Albert Boadella. La obra cierra los actos conmemorativos del cuarto centenario de la publicación de la primera parte de El Quijote que tuvieron lugar el año pasado. El espacio escénico lo forma el mismo escenario sobre el que se han dispuesto, a los lados, varias filas de butacas. Allí, una insufrible directora argentina ensaya con un grupo teatral el montaje de su particular versión en clave feminista de El Quijote. Al lugar llegan, para reparar una avería, en una moto destartalada, un fontanero y su ayudante, aunque en realidad se trata de dos pacientes escapados de un psiquiátrico. El fontanero es un ávido lector de Cervantes, cosa que fascina a los actores. A partir de ese momento se producen situaciones realmente delirantes. La obra pone al descubierto casi todas las obsesiones de Boadella, entre las que ocupa un lugar primordial "reducir la artificialidad inherente al arte teatral que tanto complace a los forenses teatrales." Sus actores mostraron un espléndido trabajo de 
interpretación. Fue uno de los mejores

espectáculos presentados en este festival.

Danza, canto, espectáculos de calle y actividades paralelas

Danza Teatro de la Habana fue la encargada de inaugurar esta edición del festival con Sonlar, un proyecto nacido en el año 2004 de la mano de Cristina Lobetto y René de Cárdenas. Ayudados de escobas, abanicos, chanclas o cacerolas esta joven compañía cubana crea, sin instrumentos musicales, su propia música y escenifica un día cualquiera en las calles de La Habana, combinando danza, percusión y canto con los ritmos caribeños. El cuerpo de los bailarines se convierte en el eje central del espectáculo y pone de manifiesto una sólida formación y una

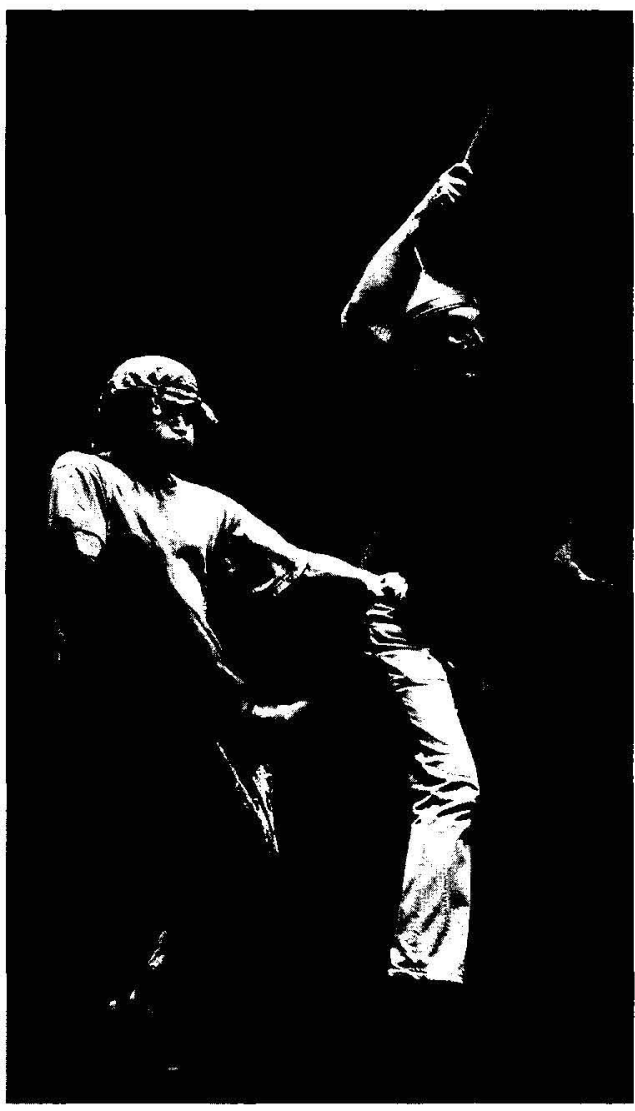

En un lugar de Manhattan Foto: Manuel Fernández. singular técnica corporal.

Chile-España-Francia se aliaron para producir $O$ divina la comedia. Purgatorio. Una madre y sus hijos en el purgatorio, de Teatro del Silencio y Karlik Danza Teatro, bajo la dirección, puesta en escena y adaptación de Mauricio Zeledón, y con coreografia y dirección de movimiento de Cristina D. Silveira. Actores, acróbatas, bailarines y músicos se unen para crear un "teatro total" en el que se denuncia de forma desgarrada los horrores de la guerra y los grandes cataclismos de nuestra época.

L'Explose presentó Frenesi, con dramaturgia de Juliana Reyes y dirección y coreografía de Tino Fernández. La puesta refiere a la fiesta de los toros vista desde adentro, en un careo entre lo humano y lo animal. El espacio escénico reproduce una morgue moderna en la que se hallan unos 


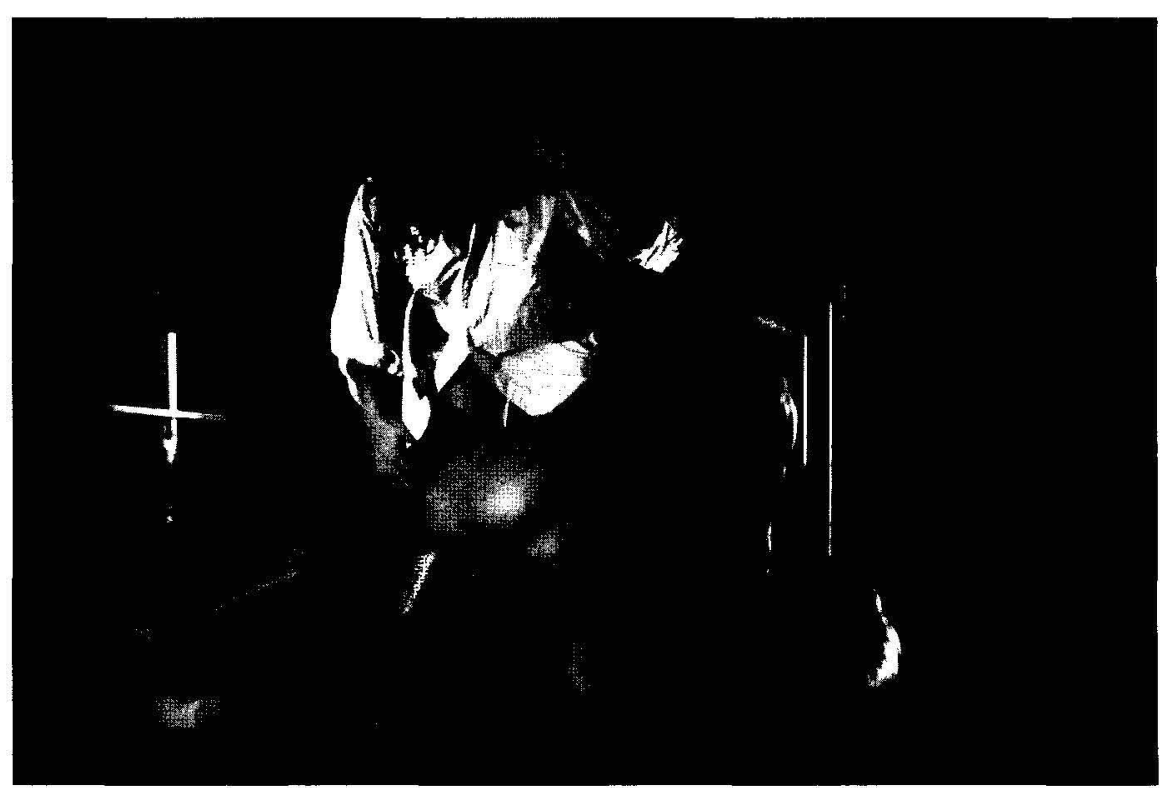

Frenesí Foto: Manuel Fernández.

cuerpos masculinos desnudos. Unas mujeres se encargan de apilarlos al borde del escenario. Los cuerpos se incorporan, se retuercen, se enfrentan, se rozan, fraguando un duelo erótico y descarnado. Impactante espectáculo el de esta compañía colombiana galardonada con el Premio Nacional de Danza 2006.

La compañía sevillana Teatro del Velador trajo a Cádiz El patio, con dramaturgia y dirección de Juan Dolores Caballero, y realización coreográfica de Trinidad Sevillano. Cinco notables bailarinas de danza clásica (convertidas en reclusas) y tres actores (en guardias) muestran el sometimiento, el control y el proceso de adaptación con pérdida de la individualidad al que está sujeto el ser humano en la sociedad contemporánea.

Teatro Símurgh (Bolivia) presentó Cantores creación y dirección de Fiore Zulli. El mismo Zulli y Carla Robertson son los encargados de llevar a escena canciones, diálogos y cuentos que han sido transmitidos de generación en generación, de un sinnúmero de países tan alejados entre sí como Colombia, Egipto, Cuba o la India.

Entre los espectáculos de calle figuran Costrini, (Argentina); y los grupos españoles: Azar Teatro con Spanish Blood-Sangria, Zanguango Teatro con El desahucio, y Totó y Cia. con É D'Oxum (España, Brasil, 


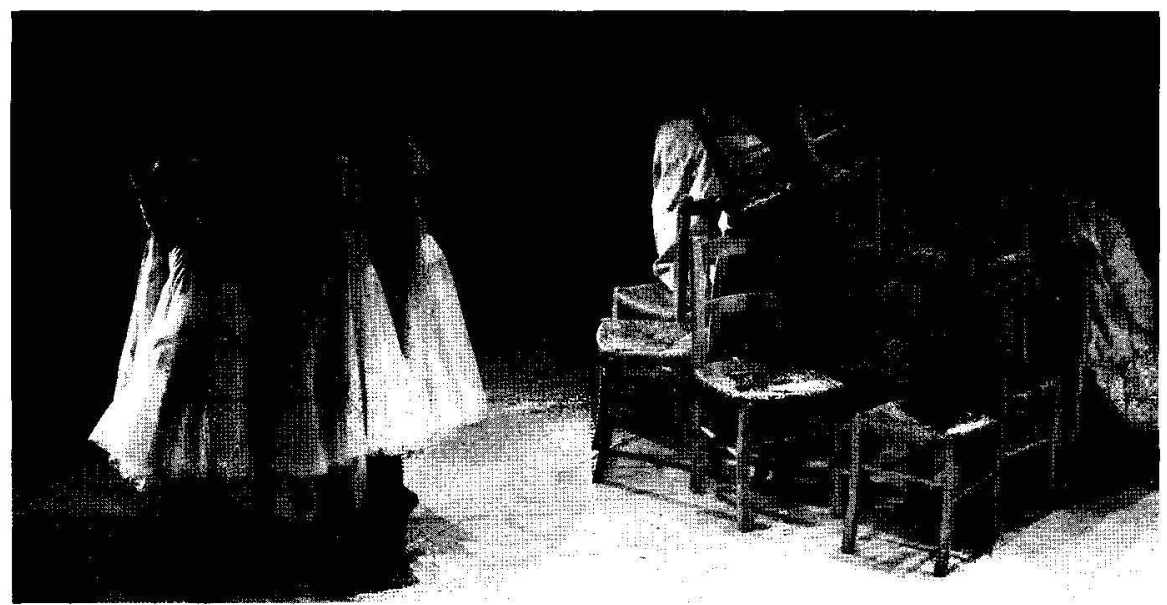

El patio Foto: Manuel Fernández.

Italia). Otros dos grupos españoles, Deambulants con Alt, espectáculo de altura que integra técnicas de circo, creación visual y clown, y Markeliñe con Carbón Club, un cabaret que saca a la superficie el mundo de la mina, fueron los encargados de clausurar el FIT callejero.

Dentro de las actividades paralelas se realizó la presentación de distintas publicaciones: Espacios de representación, editado por Lola Proaño, que contiene los trabajos del IX Encuentro de Mujeres de Iberoamérica en las Artes Escénicas; Préstame tus oidos, de José Luis Ramos Escobar; Teatro, religión y sociedad, edición de José Monleón y Nel Diago; Los aposentos del caracol, Frasquita Larrea y Sainete, de Antonio Estrada; Castañuela 70, de Tábano y Las Madres del Cordero; los últimos números de las revistas Gestos, Primer Acto, Conjunto, Estreno, Artez, Paso de Gato, Actores, Revista de la Asociación Mexicana de Investigación Teatral y Revista Galega de Teatro. Se exhibió el documental FIT N20, de Paco Rodríguez, que recorre los 20 años de historia del festival. Coordinados por Eberto García Abreu, se celebraron los foros críticos con la intervención de los grupos participantes y encuentros de creadores, críticos e investigadores, con la presentación de trabajos a cargo de José Luis Ramos Escobar, Vivian Martínez Tabares, Carlos Herrera, Luis A. Rosas, Alberto Sarraín, Nel Diago, Lola Proaño, Hilda Saray Gómez, José Ramón Alcántara, Alberto García Sánchez, Abel González Melo y Alicia del Campo. El grupo teatral puertorriqueño Jóvenes del 98 dirigido por Maritza Pérez Otero presentó, 
fuera de programa, tres atrayentes montajes en los que se pudo observar un buen nivel de actuación.

Larga vida al FIT de Cádiz, centro teatral anual de intercambio de ideas y de dramaturgias contemporáneas de la escena latinoamericana y española.

Carleton University

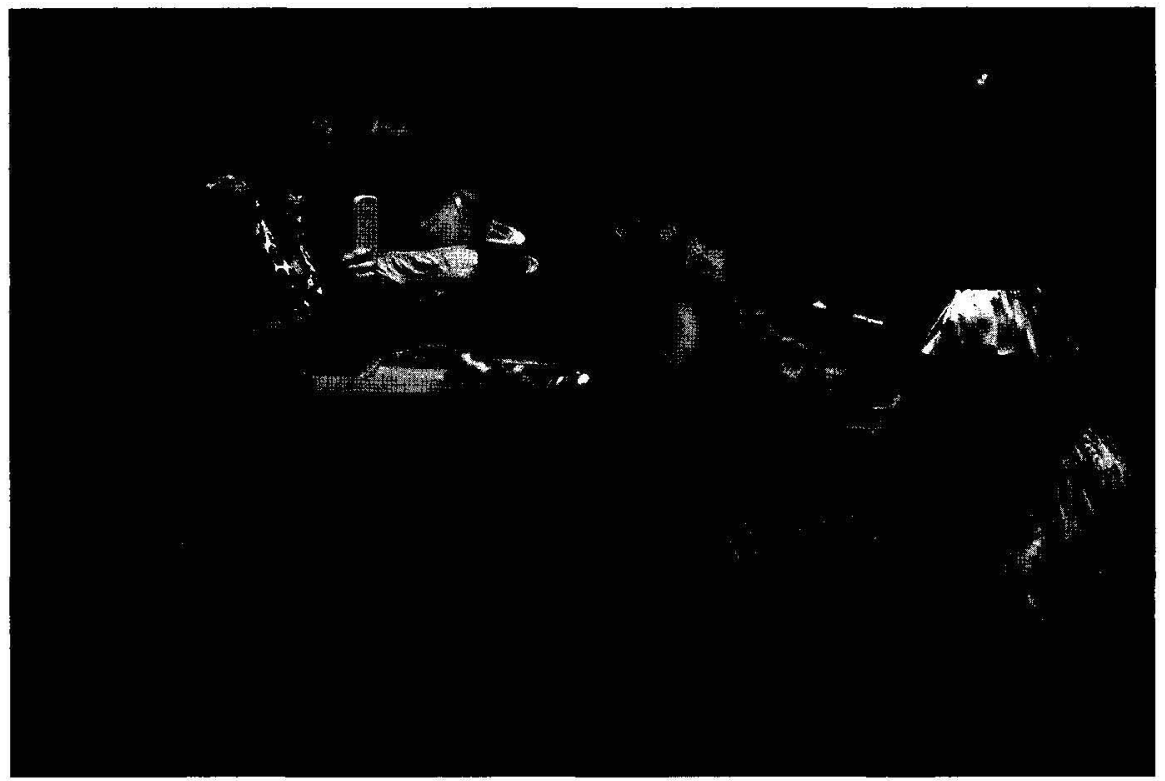

Sonlar Foto: Manuel Fernández. 